\title{
Sustained Oscillations of Insulin, Glucagon, and Somatostatin from the Isolated Canine Pancreas during Exposure to a Constant Glucose Concentration
}

\author{
John I. Stagner, Ellis Samols, and Gordon C. Weir, Veterans Administration \\ Medical Center and the Department of Medicine, University of Louisville \\ School of Medicine, Louisville, Kentucky 40232; Department of Medicine, \\ Medical College of Virginia, Richmond, Virginia 25298
}

\begin{abstract}
A B S T RACT Canine pancreata were perfused in vitro to examine whether hormone cycles could be demonstrated without hepatic or central nervous influence. Insulin, glucagon, and somatostatin demonstrated regular sustained cyclic secretion from the in vitro canine pancreas. Oscillations were noted for over 200 min during the infusion of a constant glucose concentration. Insulin demonstrated a 10 -min period with a range of $8-12 \mathrm{~min} / \mathrm{cycle}$. Somatostatin had a $10-\mathrm{min}$ period with a range of $8-11 \mathrm{~min}$. Glucagon had a period of $8.6 \mathrm{~min}$ with range of $6-10 \mathrm{~min}$. These periods do not allow glucagon to be consistently $90^{\circ}$ out of phase with insulin and somatostatin.
\end{abstract}

When glucose was increased from 88 to $200 \mathrm{mg} / \mathrm{dl}$, insulin cycles persisted but on an elevated base line, demonstrating that cycles react to glucose changes but are not dependent upon them. Cycles were disrupted by infusions of dopamine, apomorphine, epinephrine, and acetylcholine, but were reestablished. Autonomic blockade by both single and combined infusions of atropine (cholinergic), propranolol, and dibenzyline (adrenergic) had no effect on cycles. These results suggest that, in vitro, there is an intrinsic rhythm of hormone secretion by the pancreas despite a constant glucose level. The production of in vitro cycles requires the presence of a driving oscillator or pacemaker within the pancreas and the coordination of islets by pacemaker-islet communication, presumably by a nonadrenergic neural system. In vitro oscillations may Indicate that the pancreas is the driver or Zeitgeber of in vivo glucose-insulin cycles.

This work was presented in part at the 61st Annual Meeting of the Endocrine Society, Anaheim, Calif., 13-15 June 1979, and in abstract form (1979. Program and Abstracts of the Endocrine Society. 61: 74).

Received for publication 26 December 1979 and in revised form 30 January 1980.

\section{INTRODUCTION}

Plasma glucose and insulin have been suggested to be related, or co-regulated, by a negative feedback mechanism based upon hepatic glucose release (1-3). The release of glucose in bursts or momentary excess has been postulated to induce a cyclic oscillation of both glucose and insulin $(1,4,5)$. In vivo, the liver, with its suggested cyclic autoregulated glucose release, has been assigned the role of the originator or Zeitgeber (6) of the oscillations, even though minimal insulin is required for hepatic maintenance and autoregulated glucose release $(1,4,7)$. Such oscillations have been noted in monkeys, man, and dogs in vivo $(1,4,5)$.

Theories concerning basal glucose-insulin assume a relationship dependent upon glucose (1-4), although some modulation by the autonomic nervous system has been suggested $(1,2)$. The experimental removal of the pancreas from external hepatic and nervous influences would demonstrate that cycles exist despite a constant basal glucose concentration and may indicate that the pancreas is the driver or Zeitgeber (6) of the in vivo glucose-insulin cycles.

\section{METHODS}

Fasting mixed breed German shepherd dogs weighing 20-25 $\mathrm{kg}$ were used as pancreas donors. Methods used in pancreatectomy and perfusion are described in detail elsewhere (8). Throughout the studies, perfusate glucose concentration was maintained at $88 \mathrm{mg} / \mathrm{dl}$ except where specifically noted. In those cases, $200 \mathrm{mg} / \mathrm{dl}$ glucose perfusate was used. The perfusate consisted of Krebs-Ringer buffer, $\mathrm{pH}$ 7.3-7.4, containing 4\% dextran, electrolytes, and a 1-mM amino acid mixture (8). Temperature, pressure, and flow rate were monitored throughout each perfusion of 215 min. Samples were obtained from the efflux at 1-min intervals by means of a fraction collector.

Efflux glucose was monitored at 1-min intervals by a glucose oxidase procedure (Sigma Chemical Co., St. Louis, 
TABLE I

Comparison of In Vitro Pancreatic Hormone Cycles

\begin{tabular}{|c|c|c|c|c|c|c|}
\hline Glucose & Hormone & Peak mean* & Base-line mean & $\begin{array}{c}\text { Ratio } \\
\text { peak/total }\end{array}$ & $\begin{array}{c}\text { Cycle mean } \\
( \pm \text { SEM })\end{array}$ & Range \\
\hline $\mathrm{mg} / \mathrm{dl}$ & & $\mathrm{pg} / \mathrm{ml}$ & $\mathrm{pg} / \mathrm{ml}$ & $\%$ & $\min$ & $\min$ \\
\hline 88 & $\begin{array}{l}\text { Insulin } \\
(n=20) \ddagger\end{array}$ & $\begin{array}{c}4,712 \\
(2,000-18,000) \S\end{array}$ & $\begin{array}{c}9,400 \\
(3,800-19,400)\end{array}$ & $36 \pm 10$ & $10 \pm 0.3$ & $8-12$ \\
\hline 200 & $\begin{array}{l}\text { Insulin } \\
(n=4)\end{array}$ & $\begin{array}{c}19,000 \\
(5,600-45,000)\end{array}$ & $\begin{array}{c}48,000 \\
(26,000-138,000)\end{array}$ & $28 \pm 5$ & $10 \pm 0.4$ & $8-12$ \\
\hline 88 & $\begin{array}{l}\text { Glucagon } \\
(n=15)\end{array}$ & $\begin{array}{r}21 \\
(6-40)\end{array}$ & $\begin{array}{r}55 \\
(20-155)\end{array}$ & $24 \pm 4$ & $8.6 \pm 0.3$ & $6-10$ \\
\hline 88 & $\begin{array}{l}\text { Somatostatin } \\
(n=6)\end{array}$ & $\begin{array}{r}64 \\
(26-150)\end{array}$ & $\begin{array}{c}298 \\
(150-650)\end{array}$ & $18 \pm 3$ & $10 \pm 0.2$ & $8-11$ \\
\hline
\end{tabular}

* Peak concentrations are measured as concentrations above the base line as defined for each cycle.

$\ddagger n$, number of pancreases.

$\S$ Numbers in parentheses indicate range.

Mo.). Insulin, somatostatin, and glucagon were measured by radioimmunoassay and a charcoal separation technique (8). 15 pancreata were studied in vitro without further manipulation to establish the presence of distinct hormone cycles. In an attempt to disrupt cycles, 10-min infusions of acetylcholine $(5 \mu \mathrm{M})$, dopamine $(0.5-10 \mu \mathrm{M})$, apomorphine $(0.05-10 \mu \mathrm{M})$, and epinephrine $(2-10 \mathrm{ng} / \mathrm{ml})$ were employed as well as separate and combined continuous infusions of autonomic blockers, atropine $(5 \mu \mathrm{M})$, propranolol $(4 \mu \mathrm{M})$, and dibenzyline $(5 \mu \mathrm{M})$, which were begun at $90 \mathrm{~min}$ to allow control cycles to be evident from each organ examined.

Assay results were calculated and graphed using a 3-min running average to smooth the curves by reducing assay and experimental noise that appears as small spikes or shoulders on cyclic curves. This has the effect of reducing the peak amplitudes slightly and shifting each cycle $1 \mathrm{~min}$ to the right. No other mathematical curve-fitting procedures or computer enhancement of cycles or peak values was required to observe distinct hormone cycles from the pancreas. Base-line values were defined as the average of the trough values bracketing each peak or cycle. All peak values were calculated as peak height (concentration) above the base line.

\section{RESULTS}

Cyclic hormone secretions were observed from 25 of the 32 pancreata. While each demonstrated differing cycle amplitudes and base lines, the frequency or period of each cycling hormone was remarkably constant. Differences between organs were compensated for by examining the ratio or percentage of each peak to its total (peak plus base line) hormone concentration. As percentage of total, amplitudes above the base line were similar for each hormone respectively (Table I). Insulin demonstrated a $10-$ min period mean with a range of 8-12 min. Somatostatin had a similar mean period of $10 \mathrm{~min}$ with a range of 8-11 min. Glucagon was the least consistent with a mean frequency of $8.6 \mathrm{~min}$ with a range of 6-10 min. Figs. 1 and
2 are representative perfusions from two pancreases showing the relationship of insulin to somatostatin and insulin to glucagon, respectively.

As shown in Table I, glucose $(200 \mathrm{mg} / \mathrm{dl})$ increased the insulin base line and amplitude values, but did not alter the period of the cycles although the peak base-line ratio was diminished by the increased base line. Epinephrine (four pancreata), acetylcholine (three pancreata), dopamine (three pancreata), and apomorphine (three pancreata) abolished cycles during infusion by stimulating or inhibiting hormone secretion beyond the limits of the cycles $(8-10)$. Cycles were reestablished within $10-30 \mathrm{~min}$ after the infusions.

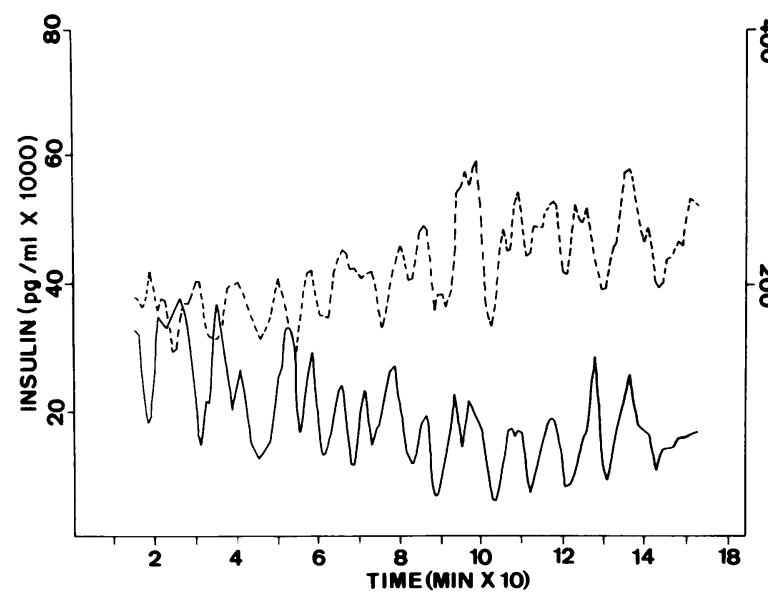

Figure 1 Insulin and somatostatin cycles. Comparison of insulin (solid line) and somatostatin (broken line) cycles from a representative single pancreas. After an initial equilibration period cycles become regular and closely matched in frequency. Cycles persisted throughout the period of study in all perfusions. 


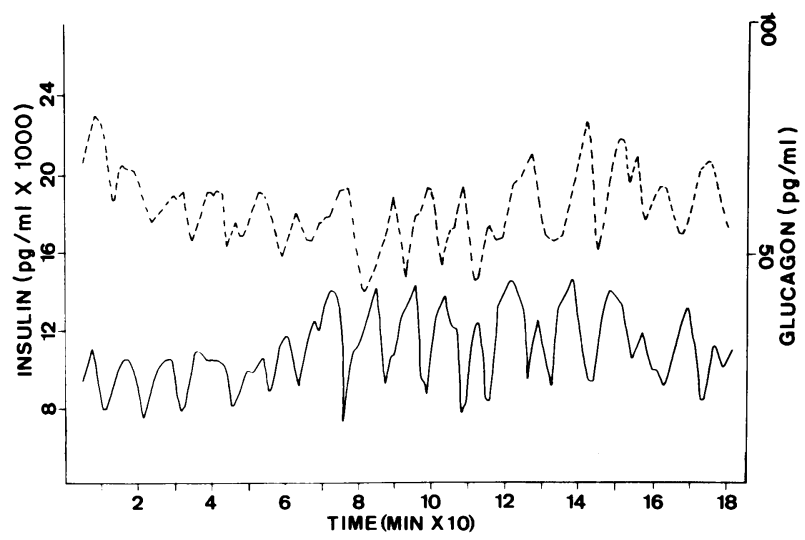

Figure 2 Comparison of insulin and glucagon cycles. Representative cycles of insulin (solid line) and glucagon (broken line) from a single pancreas before and after combined autonomic blockade by atropine, propranolol, and dibenzyline. Combined autonomic blockade (shaded area) was without effect on cycle frequency or the ratio of peak amplitude to the total secretion during each cycle. The shapes of the glucagon curves are exaggerated by the scale which is relative to insulin.

Continuous infusion, both separate and combined, of atropine, propranolol, and dibenzyline (four pancreata, respectively) had no effect on cycle period or amplitude (Fig. 2). Glucose concentration in the efflux did not change during the perfusion, nor did temperature $\left(37^{\circ} \mathrm{C}\right), \mathrm{pH}$ of 7.3 , flow rate $(20 \mathrm{ml} / \mathrm{min})$, or perfusion pressure $(30-50 \mathrm{~mm} \mathrm{Hg})$.

\section{DISCUSSION}

The demonstration of regular sustained oscillations of insulin, somatostatin, and glucagon in the in vitro pancreas suggests that pancreatic hormone secretion is cyclic. Cycles persist for the duration of the experiments (3.5-4h) during the infusion of constant glucose concentrations. The in vitro pancreas is a useful and valid preparation to examine hormone cycles, providing a controlled environment free of hepatic and external central nervous modulation. Since samples are taken directly from the efflux, rather than systemically, undiluted hormone concentrations enable in vitro cycles and interhormone relationships to be easily observed without the aid of artificial mathematical models or computer enhancement.

The timing of in vitro cycles approximates those observed in vivo in both man and monkeys $(1,4)$ to a remarkable degree considering they are of different species. As the glucose variable was removed in vitro, the relationship between hormones was made more evident. Insulin and somatostatin were in phase with constant cycles. Glucagon cycles were more variable and difficult to measure, however, they constantly demonstrated a smaller period range than insulin. The glucagon cycles were not $90^{\circ}$ out of phase with insulin as has been reported in monkeys (4). It may be postulated that glucagon is less entrained (6) by the pacemaker than is insulin or somatostatin.

In vitro hormone cycles are independent of glucose at basal concentrations; therefore, they are not the result of glucose cycle entrainment as suggested from in vivo results $(1,4)$. Cycles respond to changes in glucose concentration, an increase from 88 to 200 $\mathrm{mg} / \mathrm{dl}$, by a change in net hormone release. At 200 $\mathrm{mg} / \mathrm{dl}$ glucose, both the base-line and peak insulin concentration increased, without an alteration in period (Table I), whereas glucagon levels decreased. Cycle curves are "monophasic," in terms of the canine in vitro pancreas, rather than "biphasic." Cycles may result from the release of a postulated fast pool of hormones (11) that has a rapid turnover rate, whereas base-line levels are maintained by a slower tonic secretion from a slow metabolic pool. The fast pool may be replenished from the slow pool, which may provide a stimulus for constant hormone synthesis.

The canine pancreas is a large organ, $75-80 \mathrm{~g}$ and $20-22 \mathrm{~cm}$ in length from a 20 to $25-\mathrm{kg} \mathrm{dog}$. In an organ of this size, regular cycles can not be maintained without an intrinsic pacemaker to drive the cycles and communication between the pacemaker and individually secreting islets to bring them in to register. Secondary cycles, if they occur, may be the result of paracrine effects. Presumably pacemaker islet communication is neural, through a nonadrenergic, noncholinergic (nonmuscarinic) system, since atropine, propranolol, and dibenzyline were without effect. Recently it has been shown that the endocrine pancreas is richly supplied by peptidergic nerves that supply and ramify from pancreatic ganglia (12). It may be the ganglia that function as the pacemaker, which coordinates islets by a peptidergic nervous system. The pacemaker, or communication network, may be overridden by external neural agents in vitro. The in vitro cycles are not produced by the lack of tonic external nervous or hormonal modulation since they are present in vivo $(1,9)$ with similar periods. Moreover, the in vitro pancreas has been shown to retain its sensitivity to both neural agents and hormonal influence $(9,13,14)$. The present data cannot differentiate whether insulin or another substance (12) is the primary oscillator after the pacemaker and serves to drive islet cycles. Certainly, in vitro, the driving oscillator is pancreatic and not a result of glucose changes. It is quite possible that in vivo glucose/insulin cycles are driven by the pancreas.

\section{REFERENCES}

1. Long, D. A., D. R. Matthews, D. Phil, J. Petro, and R. C. Turner. 1979. Cyclic oscillations of basal plasma glucose and insulin concentrations in human beings. N. Engl. J. Med. 301: 1023-1027. 
2. Sacco, L., P. E. Cryer, and R. S. Sherwin. 1979. Blood glucose regulates the effects of insulin and counterregulatory hormones on glucose production in vivo. Diabetes. 28: 533-536.

3. Malaisse, W. J., A. Sener, A. Herchuely, and J. C. Hutton. 1979. Insulin release: the fuel hypothesis. Metab. Clin. Exp. 28: 373-386.

4. Goodner, C. J., B. C. Walike, D. J. Koerker, J. W. Ensinck, A. C. Brown, W. E. Chideckel, J. Palmer, and L. Kalnosy. 1977. Insulin, glucagon and glucose exhibit synchronous, sustained oscillations in fasting monkeys Science (Wash. D. C.). 195: 177-179.

5. Anderson, G. E., Y. Kologlin, and C. Papadopoulos. 1967. Fluctuation in postabsorptive blood glucose in relation to insulin release. Metab. Clin. Exp. 16: 586-596.

6. Krieger, D. T., editor. 1979. Endocrine rhythms. Raven Press. New York. 1-87.

7. Davidson, M. B. 1979. Autoregulation by glucose of hepatic glucose balance: permissive effect of insulin. Diabetes. 28: 379.

8. Samols, E., and G. C. Weir. 1979. Adrenergic modulation of pancreatic A, B, and D cells. $\alpha$-Adrenergic suppression and $\beta$-adrenergic stimulation of somatostatin secretion, $\alpha$-adrenergic stimulation of glucagon secretion in the perfused dog pancreas. J. Clin. Invest. 63: 230-238.

9. Hermansen, K., S. E. Christensen, and H. Orskov. 1979. Characterization of somatostatin release from the pancreas. Diabetologia. 16: 261-266.

10. Samols, E., J. Stagner, and G. Weir. 1979. Presynaptic dopaminergic modulation of pancreatic insular secretion. Diabetes. 28: 371. (Abstr.)

11. Guyton, J. R., R. O. Foster, J. S. Soeldner, M. H. Tan, C. B. Kahn, L. Koncy, and R. E. Gleason. 1978. A model of glucose-insulin homeostasis in man that incorporates the heterogenous fast pool theory of pancreatic insulin release. Diabetes. 27: 1227-1241.

12. Larsson, L. I., and J. F. Rehfeld. 1979. Peptidergic and adrenergic innervation of pancreatic ganglion. Scand. $J$. Gastroenterol. 14: 433-437.

13. Iversen, J., and D. W. Miles. 1971. Evidence for a feedback inhibition of insulin on insulin secretion in the isolated, perfused canine pancreas. Diabetes. 20: 1-9.

14. Samols, E., and J. Harrison. 1976. Intraislet negative insulin-glucagon feedback. Metab. Clin. Exp. 25: 14431447. 